\title{
Modular complexity and remix: the collapse of time and space into search
}

Eduardo Navas

\section{(2) OpenEdition}

\section{Journals}

\section{Electronic version}

URL: http://journals.openedition.org/anthrovision/324

DOI: 10.4000/anthrovision.324

ISSN: 2198-6754

\section{Publisher}

VANEASA - Visual Anthropology Network of European Association of Social Anthropologists

Electronic reference

Eduardo Navas, "Modular complexity and remix: the collapse of time and space into search ", Anthrovision [Online], 1.1 | 2013, Online since 02 August 2013, connection on 19 April 2019. URL http://journals.openedition.org/anthrovision/324 ; DOI : 10.4000/anthrovision.324

This text was automatically generated on 19 April 2019

(c) Anthrovision 


\title{
Modular complexity and remix: the collapse of time and space into search $^{1}$
}

\author{
Eduardo Navas
}

Three case studies of YouTube videos used to analyze image editing in relation to search patterns

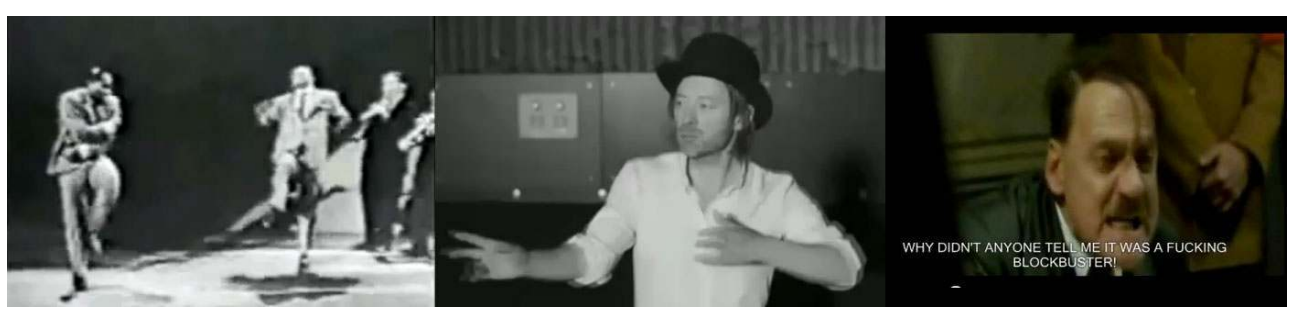

VIDEO STILLS OF THE CHARLESTON STYLE, LOTUS FLOWER, AND DOWNFALL MEMES.

1 This article reflects on the implications behind search algorithms which provide people with material that is relevant in correlation to a hierarchy of supposed importance which may reach great popularity, and perhaps even go viral (large circulation online) according to the use of key terms known as meta-data. It evaluates the aesthetics of search made possible because of what I call modular complexity, meaning the ability to function within a system of modules that are autonomous but that also effectively inform and redefine each other. ${ }^{2}$ This leads to the collapse of time and space into search, meaning that the postmodern gave way to a sense of historical dismissal, which is fully at play in networked culture as ahistoricity. This shift, which informs emerging markets on the global network, gives new purpose to interdisciplinary methodologies across fields of research in the social sciences as well as the humanities.

2 This analysis demonstrates that online queries form threads whose content can take great effort to remap if one wants to understand how time plays a role in the development of modular material. This leads to a theory of modular complexity in relation to Remix. Search repositions all forms of production on an ahistorical layer when 
search engines provide people with access to material of interest, based on a process of recycling of information which, when desired to create viral economic flows with selected objects, encourages recursion (often of remixes). This repetition or recycling is not analyzed qualitatively, but quantitatively. This means that material which is often privileged at the top of a query is not necessarily of the best quality, but simply the most popular.

3 My case studies consist of a set of YouTube videos whose production was partly influenced by query results. The search results are based not on the video's time of production, but on their viral status. Videos made at a later date may consistently supersede a video made earlier if the latter proves to be more popular than the former. To attain an in-depth understanding of this recurrence, it is also necessary to understand the different configurations of search on engines such as Bing and Google, in juxtaposition with social media services such as Flickr and YouTube. The gathering of material from YouTube took place between September 2010, and March 2011. These results were then again reviewed during June and July of 2011 to assess their relevance to search engines and Flickr. Because it is likely that the search results on the case studies will be different by the time article text is published, I provide a set of visualizations online to evaluate the results during the times described, cited in the footnotes. My methodology is cultural analytics, a combination of qualitative and quantitative analysis which I implement to visualize the YouTube video case studies.

4 To explain the relation of time, space and search in terms of Modular Complexity and Remix, this article first examines the relation of these variables according to the shift from postmodernism to globalization. It then examines the relation of ahistoricity and search, moving on to how search functions on engines such as Google and Bing. Search is analyzed on Flickr and YouTube, and then by three YouTube case studies. The analysis of search on these platforms shows how modular complexity and Remix play a role in new forms of network production.

\section{The Collapse of Time and Space into Search}

5 In postmodernism what is certain is that the question of what postmodern is was never answered. To explain the reasons for this conundrum would require an entire volume, which would be a mere fragment in the extensive debate about what postmodernity and postmodernism could possibly be. In this article, I focus on one of the key elements in postmodernism that has become important in the era of globalization: the collapse of time into space. This phrase is a direct reference to Fredric Jameson's theory on the cultural logic of late capitalism:

"[...] I think it is at least empirically arguable that our daily life, our psychic experience, our cultural languages, are today dominated by categories of space rather than by categories of time, as in the preceding period of high modernism." ${ }^{3}$

6 I prefer Jameson's evaluation of postmodernism over others when discussing contemporary issues of networked culture, ${ }^{4}$ because of my long-term empirical observation of what has actually taken place since the postmodern condition began to be discussed during the 1980s, when the postmodern was manifested in architecture, art and design, and media. Arguably, the most relevant postmodern element came at the end of the decade. This was in 1991 when the rising popularity of cable news networks, such as CNN offered real time news, as the action happened on the ground. This moment provides 
evidence of the move of culture from postmodernism to globalization, a transition that became apparent in the first Gulf War. Paul Virilio elaborates:

"The morality of the end justifies all the mediated or political means, but this end is no longer that of a conflict concerning this or that country; it is primarily the end of the delay [délais], the imperious necessity of an absolute proximity between intentions and action." ${ }^{5}$

Virilio argues that when the world enters globalization, space is privileged over time, and one can focus fully on the moment of experience, disregarding the process that makes such moment possible. The difference from Jameson's observation of postmodernism is that there is no longer a delay, and therefore no apparent time to reflect critically, not even briefly. This presents a challenge to cultural critics. Jameson has acknowledged that while postmodern questions differ from those of globalization, it is necessary to focus on the latter, as the questions former will recur:

“... I do think we have an interest in at least provisionally separating this now familiar postmodern debate from the matter of globalization, all the while understanding only too well that the two issues are deeply intertwined and that positions on the postmodern are bound to make their way back in eventually." 6

Consequently, the postmodern debate is elusively intertwined with globalization, and it is at a crux where much discussion on cultural production is taking place. ${ }^{7}$

If we consider Virilio's proposition and Jameson's observations on globalization, what is crucial is the direct collapse of time into space, and the privileging of the now, of just-intime aesthetics. ${ }^{8}$ I refer to this recurrence in networked culture as 'constant updates'. ${ }^{9}$ Google News, Facebook, Flickr, Wikipedia and almost every major online resource dependent on constant updating. The moment updates cease on any online resource is the moment when such resource becomes irrelevant. At the beginning of the twenty-first century culture lives in the now, in a time when the past is called up from an archive that is a powerful tool for the enhancement of knowledge, as well as the backbone of the lucrative evaluation of emerging markets. This becomes evident when we consider the controls that web 2.0 technology has put in place.

\section{Historicity and Search}

10 If postmodernity privileged space over time, it did so in terms of simulacra; as a spectacular form meant to be contemplated statically. This was more of a sensation, an aesthetic that could still be analyzed with some critical distance due to the delay that was still at play in communication.

11 However, in the time of globalization (the period of networked culture), the collapse of time into space is real - yet truly immaterial (as it is the production of information that predominates) - thus, paradoxically redefining material reality as a constantly updated spectacle. Its definition is fully contingent upon an informational layer that converts localities into glocalities ${ }^{10}$ with the support of global online communication. Chat and video-communication with platforms such as Skype and Google-chat make the delay in communication practically non-existent. The now is currently a growing market which is best expressed in social media. All of these technologies are manageable because the large amount of information produced is organized into databases, which rely on search to be of efficient use to diverse online communities. 
In networked culture databases, which are in essence archives, reposition the relation of historicity and history (the quality of historical authenticity), on an emerging cultural layer, to which I will refer as ahistoricity. The value of history as it becomes archived with modular technology is relevant because it serves the purpose of translating cultural value to speculative value on to monetary value. Time and space, with the possibility of just-intime delivery, become embedded modularly in search to help in the proper transfer of such values in relation to the constant flow of information privileging the now, that is the aesthetics of constant updates.

\section{Search in Google, Bing, and Yahoo!}

13 Search as a basic feature was designed to help online users find their way through the growing information of the World Wide Web and Internet. Yahoo! (launched in January 1994) is one of the first portals to help organize information online; however, it was not initially designed as a search engine as it is conventionally understood in Web 2.0. It was the launch of Google in January 1996 that established the principles of search as they are currently executed by almost all search engines. ${ }^{11}$ Bing (formerly MSN search, and launched in May 2009) is a search engine that very much borrows from previously explored possibilities by Yahoo! and Google. At the time of writing, Bing also provides search services for Yahoo! Bing appears to promote a close relationship to social media, and collaborates with Facebook to develop advanced and more personal searches based on Facebook members' recommedations..$^{12}$ In reality all three online resources are developing software tools that link their services to social media.

Google has developed a ranking algorithm (which they refuse to make public) which is in part based on the peer review process of academia. ${ }^{13}$ Google query results rely mainly on the quality of content. How they define this quality, however, is not completely clear, but based on their documentation on search optimization, it appears to consist of the combination of original content, the number of links such content develops, and the 'quality' of the sites that link to the content. This is a key element which search engine optimizers must keep in mind to design websites with the best chance of appearing in the first pages of a search engine query. Bing and Yahoo! have adopted similar guidelines as Google, so all three engines offer similar results, with some differences in how they place ads for profit on their pages. ${ }^{14}$ We will not dwell on the commercial aspect of these online services, because this analysis concerns the search results themselves.

No matter how a website finds its way to the first pages of these three search engines, what becomes clear is that they will only appear once if there is a vast amount of content available on the subject. ${ }^{15}$ To prove this, I performed a search on the term 'remix', because I am familiar with the term and have a good understanding of material that has been produced about it. In all three engines a user is likely to find about the same 5 of 10 top results. The following websites are featured in the first page by all three engines: 'Remix - Wikipedia, the free encyclopedia', ${ }^{16}$ 'Remix - Remix.nin.com', ${ }^{17}$ 'Remix Remixes, Mashups and Covers!', ${ }^{18}$ 'Re-Mix Vintage Shoes', ${ }^{19}$ 'Remix: Making Art and Commerce Thrive in the Hybrid Economy'. ${ }^{20}$ Google offers these top choices out of about 839,000,000; Yahoo! out of 22,100,000; and Bing out of 20,300,000. ${ }^{21}$ Their ranking varies according to each engine's specific algorithm, but the algorithms are similar enough, and provide the same results at least in the first few pages. 

what is evident and relevant for this analysis is that as users move through a deep search beyond the first page, it is unlikely for a link to be repeated on any of the engines if the term is generic enough or there is a massive amount of content on the subject of query available online. Repetition will happen for a website, but probably not of exactly the same page. The engines are interested in unique content and therefore are not optimized to provide links to repeated webpages. In fact Google has a filter against such redundancy. When searching a term for which the same content is repeated, it omits the less 'reliable', or 'popular' sites, with an option for the user to look at those sites if desired. This is made possible with a link that states 'Repeat the search with the omitted results included'.22 redundant results from their query. Such information may recur, but if so, it is likely because optimizers have deliberately reconfigured information for websites to appear more than once. This may not be too relevant given that online users are unlikely to peruse more than the first three pages on any query. ${ }^{23}$ This means that uniqueness is the basic rule for the top results (the head) of any search, and that repetition may happen in pages found in the tail (vast amount of niche information). This is a different scenario from that encountered by users on more insular databases, such as Flickr and YouTube, where redundancy is used to give viral content value which, when popular enough, may make its way to the head of a query on search engines such as Google.

\section{Search in Flickr and YouTube}

Flickr and YouTube use redundancy to implement search in ways that differ from web search engines. For both Flickr and YouTube, searches were performed on material that was available to everyone. I examine first Flickr, and then YouTube.

Search on Flickr functions differently from search engines and YouTube. On Flickr, the relation of meta-tags to the number of posts by a single user is of great importance, in relation to three options for an initial search: Relevant (its default), Recent, and Interesting. These settings play a large role in the way search is experienced, and I will discuss them in terms of time and space in later sections.

21 I selected Flickr's default settings of 'relevant' and searched for 'remix'. After the first page results, for several pages one can find the content contributed by the same member, 'Yes Becky'. ${ }^{25}$ Images are never repeated; the vast diversity of images contributed by the single user appears to give her prevalence over others who may also include the term remix as a tag, or part of a tag. 'Yes Becky' uploaded her content under 'Wardrobe_remix', a term that is followed and used by 7,235 members. The vast number of images tagged with a popular term places 'Yes Becky"s contribution at the head of the long tail. In this case it is evident that popularity goes to the member who can contribute the most in relation to a term that in turn may become popular if enough members declare an interest in it by joining a group.

A second query of the term 'remix culture' gives similar results. After the first page, the user 'Remix Clothing Taipei' dominates the content for about three pages, and then other members' contributions appear. ${ }^{26}$ In this case two separate tags are relevant: 'remix' and 
'street culture'. 'Remix Clothing Taipei', however, does not appear to be part of a group with a large number of members.

The conclusion that could be derived from these two results is that Flickr privileges content from users that upload a large amount of images. This is true as long as the term one searches for does not have a large number of contributors at the head. For instance, when doing a query on the term 'music remix', a diverse number of contributions appear for the first four pages. ${ }^{27}$ Beginning on page five, however, contributions from the same member, 'Al Burque' appear for several pages. The relevant tags in this case are 'music' and 'remix'.

The reasons why the particular contributors dominate the search results is to do with the large number of images they uploaded under the respective meta-tags. When looking at the users' profiles, one becomes aware that they are very active and often have several sets of pictures to share under different sets and galleries. They are also part of Flickr communities. So the member's overall role in Flickr appears also to be an important element in search results.

What can be assessed with certainty from these three searches is that Flickr privileges large contributions from specific individuals, so a Flickr member potentially can dominate a search for several pages. An important variable for this analysis which will be discussed further below is that the results of images in Flickr are not presented chronologically by default, which is also the case with the search engines previously discussed. Google and Flickr do provide a setting for the most recent information available, but this is not what they are interested in presenting first. Rather they provide material that appears to be of importance in relation to their particular algorithms. This is relevant to the collapse of time and space search, informing the layer of ahistoricity, as previously discussed. Before considering the implications of the relation of ahistoricity and search, in Flickr and search engines however, I consider how search functions on YouTube.

YouTube was launched in April 2005, and was bought by Google in November 2006. ${ }^{28}$ Search on YouTube functions differently from Flickr and search engines. YouTube offers video recommendations on the right side of the webpage as soon as the next page. The results are also fine tuned as the user keeps selecting recommended videos. For example I searched again on the term 'remix' and selected from the recommendations the first video (not promoted by YouTube), which is a rap, 'BED INTRUDER SONG!!!'. I then selected from the new recommendations on the right side column 'DOUBLE RAINBOW SONG!!'. This video had previously appeared on my initial search results. As one keeps selecting videos from the right side column, it becomes evident that these recommendations appear in relation to the history of video selections, and recurring meta-data tagged to each video viewed, such as remix, rap, or hip-hop, and the YouTube member who uploaded the content; in this case, both videos were uploaded by 'schmoyoho'. ${ }^{29}$ This means that the combination of meta-data provided by YouTube members in relation to the initial query by the user are important variables in defining search results.

This indicates that query results on YouTube serve a different role from those of search engines, although there is some crossover with Flickr's approach. On YouTube queries, results are optimized to repeat material that is relevant to the query as much as possible. This is almost the opposite of what takes place with search engines. Before I analyze these 
differences and their implications in relation to ahistoricity as an informational layer that embeds time and space in search, a closer study of YouTube's approach is necessary.

\section{Three YouTube Case Studies} Flickr, and search engines. For YouTube, the major difference in direct opposition to search engines, particularly Google, is that it is optimized to repeat content (related video links) as much as possible. This tendency is obvious in searches for specific terms, which often give the result of viral memes. To explore this further, I chose three memes as case studies. ${ }^{30}$ For all three case studies there were other videos offered as recommendations, but I omitted them on the diagrams because the purpose of the visualization is to illustrate the recurrence of directly related videos from previous pages.

The three case studies I chose are The Charleston Style remixes, The Lotus Flower parody remixes, and The Downfall parody remixes. ${ }^{31}$ These studies expose particular elements of online exchange that need to be analyzed, in terms of form and content. Form will be emphasized in this article, and content will be the subject of a separate paper. ${ }^{32}$ The three case studies make apparent that the algorithm of repetition implemented by YouTube uses meta-data and search history, as described in the previous section, to provide relevant content. It will become evident that what makes the selected videos viral is also directly relevant for all YouTube videos. It is this structure that collapses time into space on YouTube. memes in 2010. I initially performed my search on Google, and selected a link to the website 'Know your Meme', which featured a blog post entitled 'The Charleston Dance Remix' ${ }^{33}$ I chose this meme because it combined three elements that are important for my long-term research on remix: music, dance and its extension to culture in terms of hip-hop. The meme presents the footage of African Americans dancing the Charleston. YouTube users appropriate the footage to portray songs they personally like.

The first remix of a performance by dancers Al Minns and Leon James was uploaded on YouTube on 11 May 2006, entitled 'Charleston Style'. The video is a mashup of the original footage, which is a single shot of the dancers coming in and out of the frame. They eventually finish dancing together. The original song recording is switched for the popular song 'Around the World' by Daft Punk. Since then several remixes have been uploaded, with most leaving the video footage alone and only switching the music. Genres include hip hop, ska, and techno among others. In this video meme the first remix is recommended on subsequent pages, once the user begins to navigate through related videos. The images below, show that the 'Charleston Style' is available on the second set of links; also note that all videos on the second page are immediately repeated on the third, and so on. 
Wide view of diagram of recommendations for the Charleston Style meme

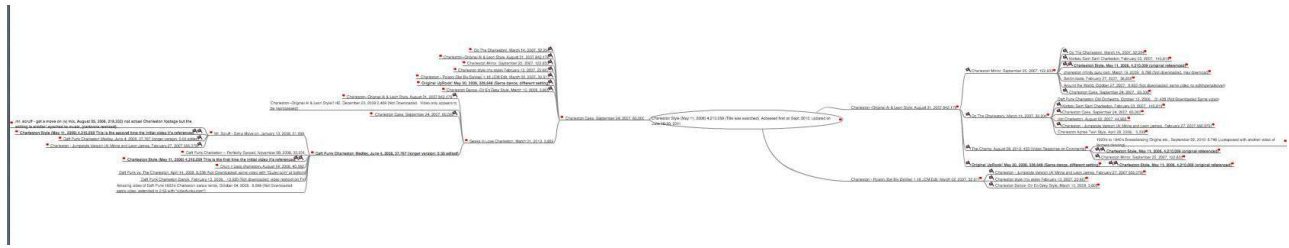

RED FLAgS REFER TO REPETITION OF CONTENT FROM PREVIOUS PAgES.

To navigate the actual visualization visit http://remixtheory.net/remixAnalytics/Diagrams/ charlestonTimeDiagram.html

Detail of diagram that shows how video remixes are repeated immediately on the next page of a video selection

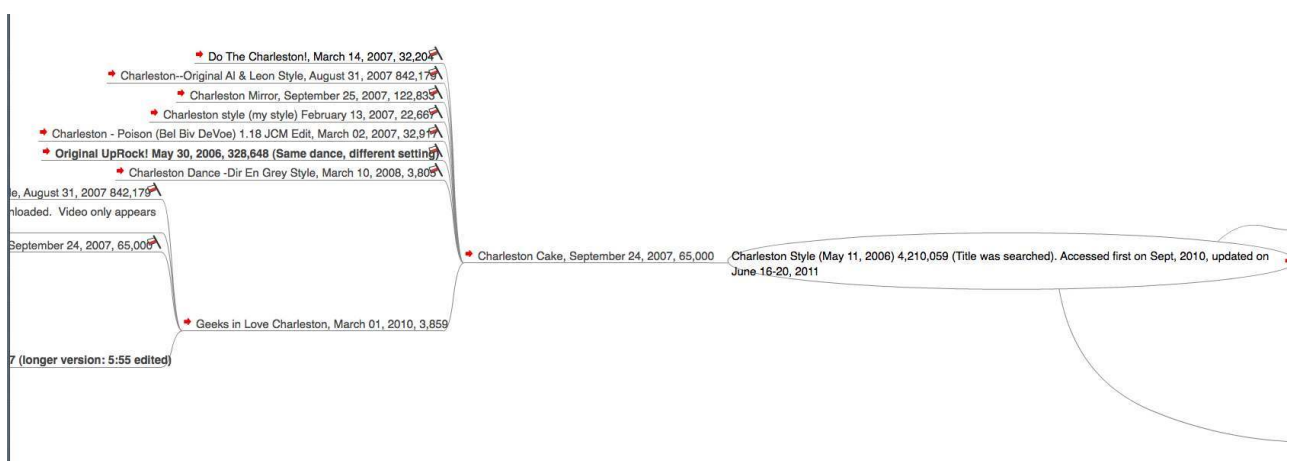

This algorithm is also evident on the visualization of my second case study, The Lotus Flower parody remixes. This meme consists of not only major reediting of the original video footage, but also, like the Charleston remixes, a vast number of songs replacing the original Radiohead recording. In this case, Radiohead posted their original official music video on 16 February 2011. The video consists of Thom Yorke dancing and singing in an empty garage-like space. The footage includes close-ups, mid and long shots of Yorke improvising his dance. When viewing the original video it is evident that Yorke's quirkiness in part is the reason why the footage was a readymade for the viral meme. The remixes began to appear, just two days after the original was uploaded, on February 18. The range of songs that replaced Radiohead's original include well known musical classics from Zorba the Greek, pop songs from the Venga Boys, as well top ten hits by Lady Gaga.

In the diagram for Lotus Flower (see images below), I chose to begin the visualization of links with the website "Death and taxes" where I read an article on radiohead's meme. ${ }^{34}$ In this case study, the repetition of videos begins on the second page and is repeated thereafter, similarly to the Charleston remix. 
Wide view of diagram of recommendations for the Lotus Flower meme

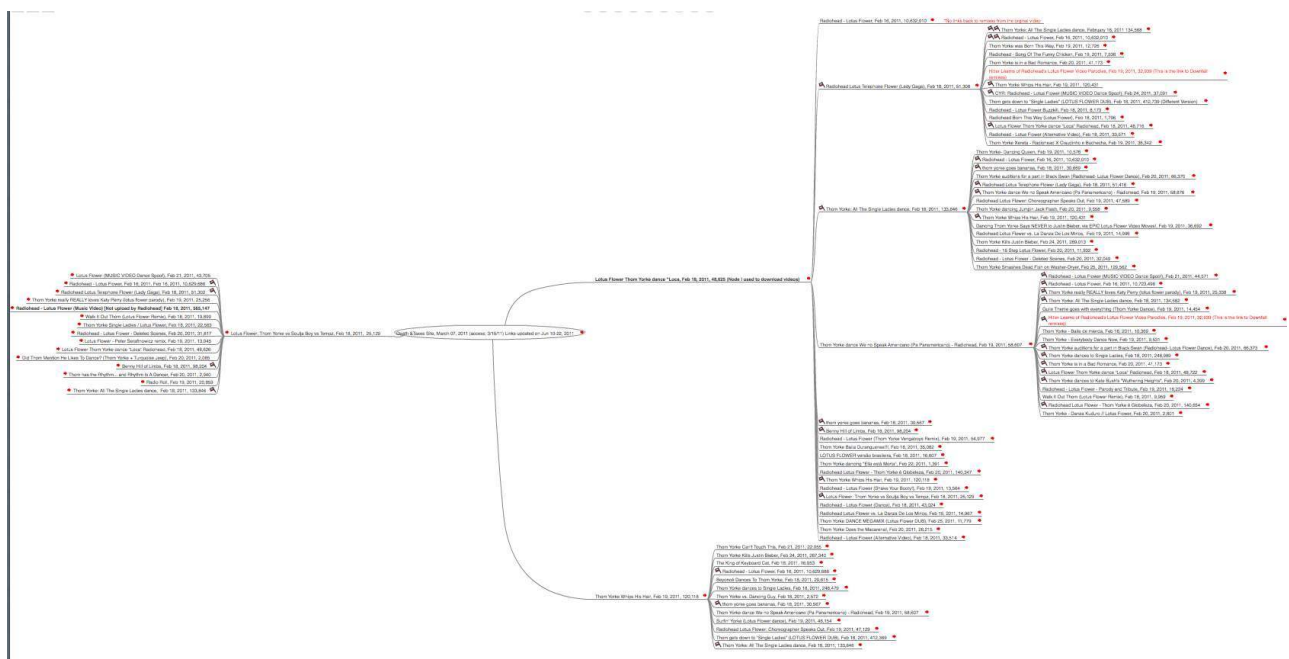

RED FLAgS REFER TO REPETITION OF CONTENT FROM PREVIOUS PAgES.

To navigate the actual visualization visit http://remixtheory.net/remixAnalytics/Diagrams/ LotusFlower.html.

Detail of diagram the shows how video remixes are repeated immediately on the next page of a video selection

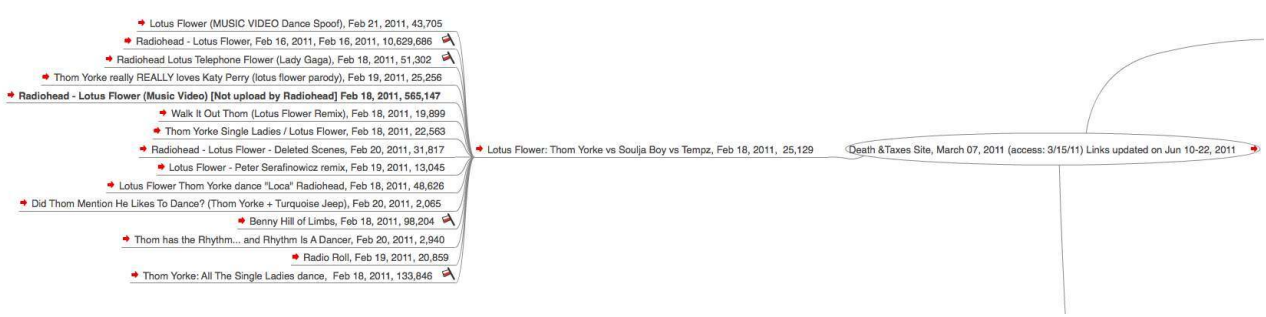

NOTICE HOW THERE ARE NOT AS MANY RED FLAgS. THIS IS BECAUSE THE MEME IS MUCH LARgER THAN THE CHARLESTON STYLE, AND OTHER RECOMMENDATIONS ARE OFFERED BASED ON META-DATA.

34 I obtained similar results with my third case study, The Downfall parody remixes. I learned about these viral videos while doing research for the Charleston Style remixes. ${ }^{35}$ These parodies consist of various excerpts from a less well known film released in 2004 entitled Downfall, about the last days of Hitler before he committed suicide. ${ }^{36} \mathrm{~A}$ few scenes have been used for the remixes and I chose the most popular, which at about 3:59 is also the longest remixed excerpt. The footage presents Hitler being told by key members of his inner circle that Berlin is surrounded and will soon fall. Hitler is upset that he has not been told the truth sooner, and rants at length until he eventually accepts the inevitability of defeat.

The parodies take the original footage, and add English subtitles that have nothing to do with what Hitler is actually saying in German. ${ }^{37}$ Instead, they present him ranting about the lack of features of the iPad, his realization that Pokemon does not exist, and his disbelief that Kanye West was extremely rude to Taylor Swift when West interrupted Swift's acceptance speech at an MTV video awards to tell her that Beyonce was a much better music artist, among many other remixes. I made a decision to focus on the Downfall remixes after I discovered one that showed Hitler being upset about the 'fact' that the 
Lotus Flower remixes had surpassed the Downfall Parodies' popularity on YouTube. ${ }^{38} \mathrm{I}$ consider this reference a way of coming full circle between the memes. With the Downfall parodies I was unable to find remixes before January 2007 and I am uncertain what the first parody may have been; many which have been featured on articles by newspapers are no longer available on YouTube. ${ }^{39}$ Nevertheless, new ones keep showing up as reflections and commentaries on current events.

As I knew of the Downfall Parodies for some time, I began my research with a direct query on YouTube for 'Downfall Parodies'. This is the first result shown on the diagram, which begins with this video (see image below). ${ }^{40}$ The repetition of material on YouTube is less immediate in this case because, as the visualization of the downfall meme shows, it is a much larger set of remixes than the other two memes. There are however some recursive results on the third and fourth pages, which begin to resemble the pattern of the other two case studies.

Wide view of diagram of recommendations for the Downfall meme

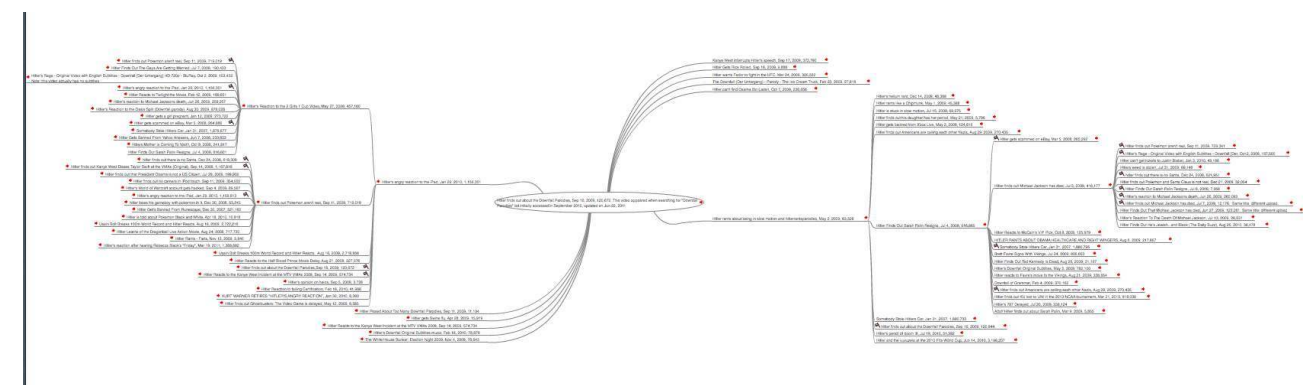

Red flags refer to repetition of content from the previous page. To navigate the actual visualization visit http://remixtheory.net/remixAnalytics/Diagrams/DownfallRemixes.html.

Detail of diagram the shows how video remixes are repeated immediately on the next page of a video selection

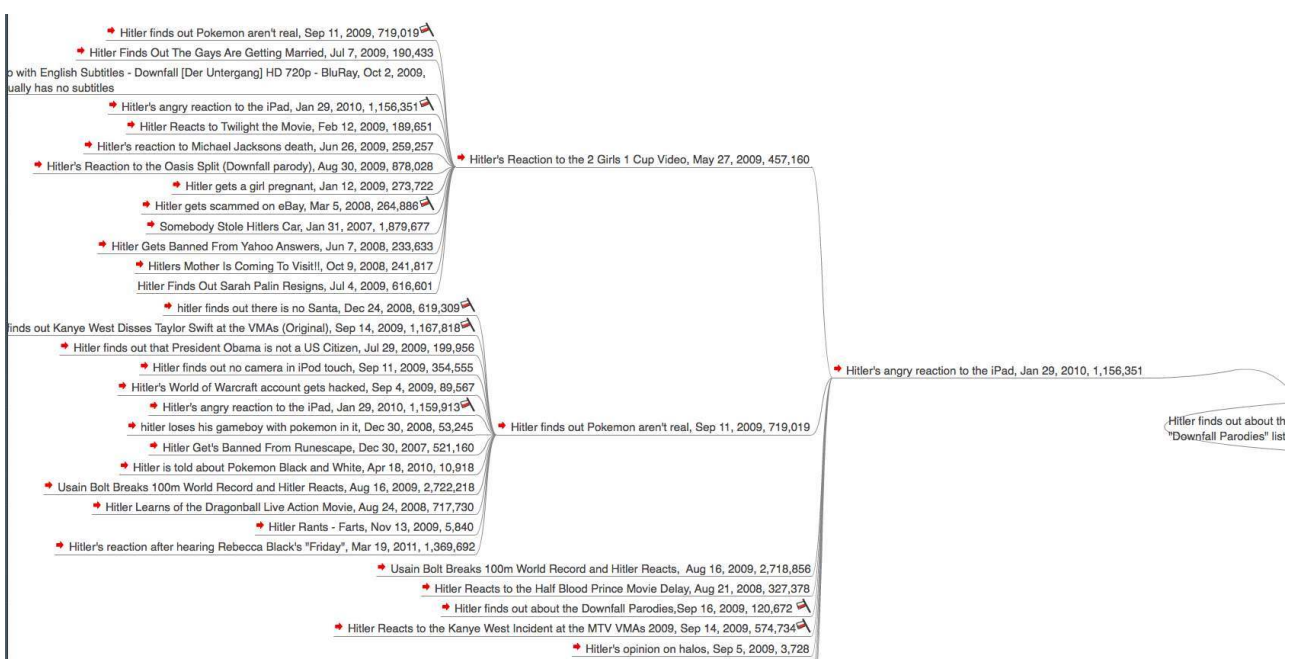

NOTICE HOW THERE IS EVEN LESS REPETITION IN THE DOWNFALL MEME WHEN COMPARED TO THE LOTUS FLOWER AND CHARLESTON STYLE MEMES. THIS IS BECAUSE THE MEME IS MUCH LARgER THAN THE OTHER TWO.

The recursion of the three case studies demonstrates that the repetition of material is less at the beginning on the first two pages of larger memes. Downfall is the largest, followed 
by Lotus Flower and Charleston. However, it is possible that the other memes will begin to take a similar form as Downfall if more videos are uploaded. In all three, the YouTube algorithm is optimized to provide diversity whenever possible. Although the same videos will not repeat immediately in the larger meme, the content that is recommended will usually be related to the meta-tag. So, even when recursion of links does not happen by the second page, relevant content is provided, that, if followed, will eventually increase in recursion.

In all three visualizations, the videos that are displayed in the first page mostly have a large number of views. These are complemented by a selection of meta-tags that make them relevant to the search. Simultaneously, the time of production appears to be irrelevant, even when videos have been uploaded on the same day, as is the case for the Lotus Flower remixes. However, in both The Charleston as well as The Downfall remixes, the large number of views is evidently privileged. This means that YouTube is optimized to provide primarily popular, rather than quality, content. The implications for this are important in terms of critical production, because for YouTube, it does not matter whether the video is of high or low quality, or what type of opinion it may promote. Another evidence of their lack of concern with quality material is that comments on YouTube are often rants, or extremely subjective comments made to elicit knee-jerk reaction from the YouTube community. YouTube's bottom line is to increase repeated visits by online users.

It should be noted that YouTube has similar search settings to Flicker's which enable the user to navigate videos in terms of relevance, time of production, popularity, and if it is highly recommended (likes or dislikes). Even if one is able to view videos chronologically, it is the popularity (relevance) that is mainly supported by YouTube.

These issues have been addressed by Jean Burgess and Joshua Green who show that YouTube is primarily a commercial site that was developed as a repository of popular videos to create revenue from advertising. ${ }^{41}$ They also found that YouTube was not originally designed to support a social network, as envisioned in Web 2.0, but has been adjusted to social media trends based on the behavior of its members. ${ }^{42}$ YouTube's success in part is because it leaves the community alone to figure things out on their own regarding communication, moderation of comments and video responses..$^{43}$ Burgess and Green consider the swift commentaries and flame wars as games among members of the YouTube community who are constantly engaged in promoting their videos to become viral. $^{44}$

41 The YouTube video visualizations on their default setting of 'relevance' show that the date of video uploads is not a primary determinant for whether or not the videos will be presented within the first choices. This resembles how Flickr presents results based on the number of images contributed by the community, irrespective of date. The key elements that play a role in YouTube's case studies are the videos' titles in combination with the meta-data, and the number of views. Of these three, the number of views takes over once the phrase searched for is presented as a primary reason for the reference. This is evident in the results for the Downfall remixes, whether searching online, or directly on YouTube, where the result for the query 'Downfall Parodies' is the video remix in which Hitler is upset about the 'fact' that the Downfall parodies are being produced even though it is neither the most popular in terms of views, nor the oldest,. This is because the title includes the term 'parody' in the meta data, and the video title includes 'downfall' as well as 'parodies'. 
42

$$
\begin{aligned}
& \text { videos that people are likely to find are the ones with the most views. One has to consider } \\
& \text { how this might effect the production of future remixes which respond and take as } \\
& \text { starting points the recommendations. This view is supported by an in-depth data analysis } \\
& \text { report funded by Telefonica (Spain): } \\
& \text { "One would expect that as more videos are made available, users' requests should } \\
& \text { be better spread across files. However, counter-intuitively, requests on YouTube } \\
& \text { seem to be highly skewed towards popular files. It is debatable whether such } \\
& \text { skewed distribution is rooted in the nature of UGC (because people primarily want } \\
& \text { to see what others have seen before), or whether better recommendation engines } \\
& \text { would mitigate the strong dominance of popular content and shift the users' } \\
& \text { requests toward less popular videos." "45 }
\end{aligned}
$$

is is also the result of the Charleston and Lotus Flower remixes, which means that the

To understand how a meme evolves based on the first remixes that a user may find can be evaluated by developing visualizations of the three cases studies that show the editing of the video footage over time. To accomplish this, I took the frames of thirty videos of each meme and sliced them in order to examine the types of editing. In the Charleston remixes the video footage stays practically the same except for a few remixes in which the footage of Leon and James dancing was used selectively as part of bigger projects. 'Mr. Scruff - Get a Move on | Charleston videoclip' is one such exception, in which the video has been reedited to match the sound (see slice detail below). Another is 'Charleston \& Lindy Hop Dance ReMix - iLLiFieD video.mix (Version)', (see below).

\section{A two-column slice visualization of 29 out of 30 remixes}

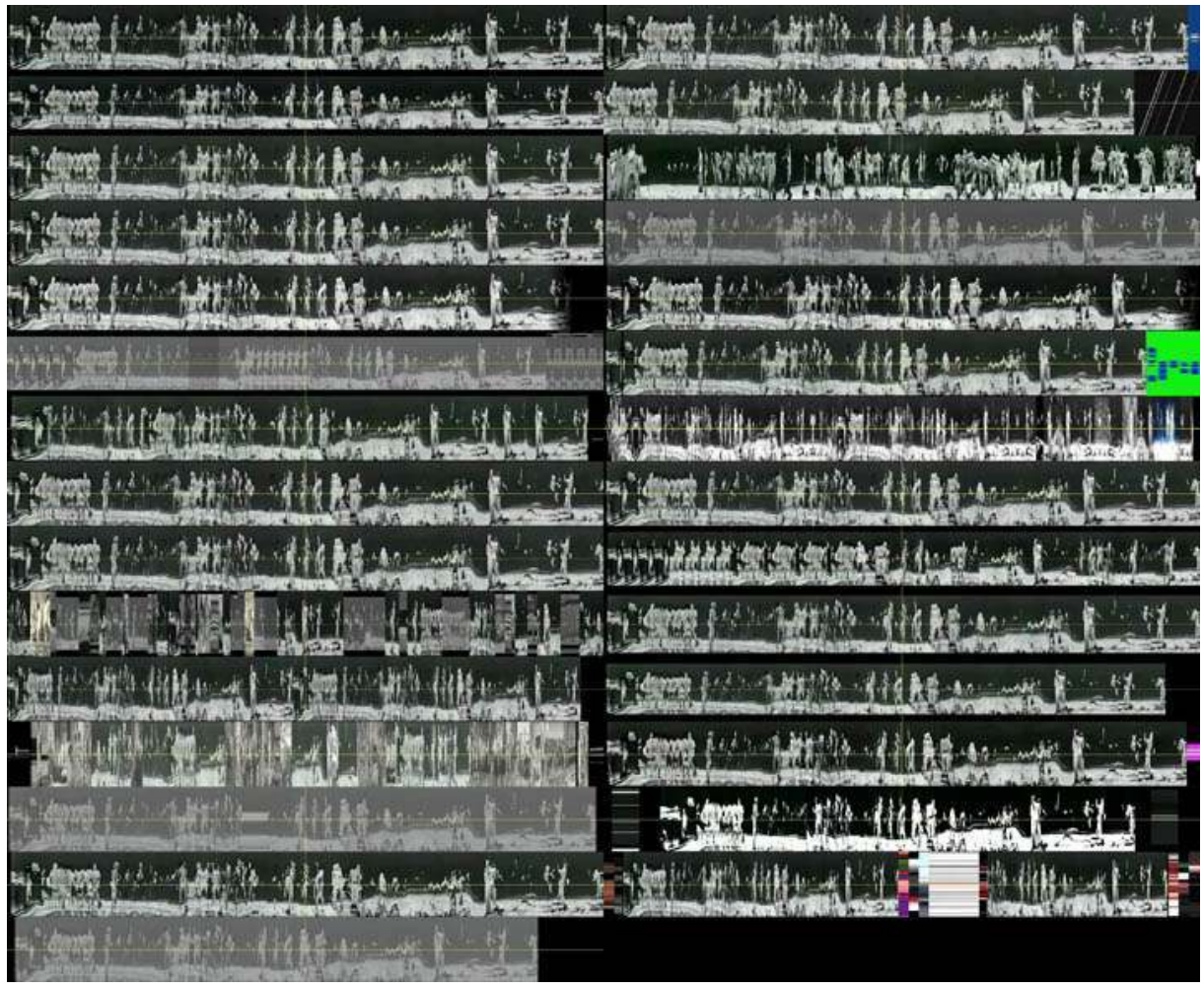

One remix was omitted because the footage is not the same performance. That video is not relevant to evaluate how the video footage of this meme is left intact.

For a full list of this visualization visit: http://remixtheory.net/remixAnalytics/ and select 'Charleston Video Slices' 
Slice visualization of 'The Charleston and Lindy Hop Dance Remix'

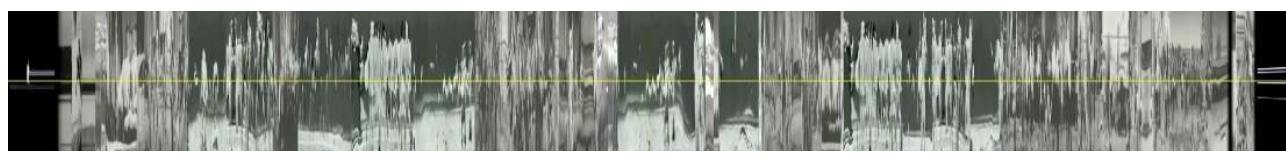

WHEN COMPARING THIS SLICED IMAgE TO OTHER SLICES IN THE TWO-COLUMN VISUALIZATION ABOVE, ONE CAN NOTICE THE SELECTIVE PROCESS WITH WHICH FOOTAgE FROM THE CHARLESTON STYLE WAS USED. THIS VIDEO IS MUCH LONGER THAN THE ORIGINAL FOOTAgE, AND HAS BEEN COMPACTED IN ORDER TO SHOW HOW THE VIDEO WAS SELECTIVELY EDITED.

TO VIEW THIS REMIX, VISIT HTTP://WWW.YOUTUBE.COM/WATCH?

V=POUPA2SW1UI\&FEATURE=PLAYER_EMBEDDED. THIS VIDEO WAS UPLOADED TO YOUTUBE 2 MAY, 2009.

Slice visualization of 'Mr. Scruff remix'

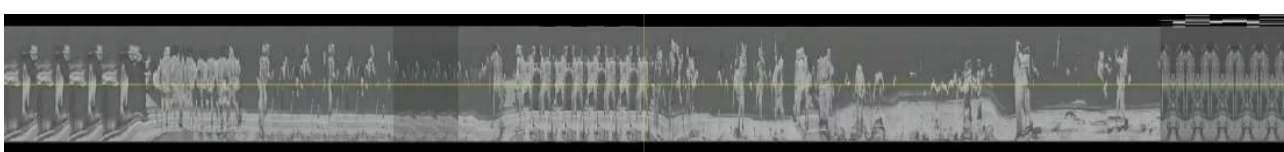

WHEN COMPARING THE SLICED IMAgE TO THE OTHER SLICES IN THE TWO COLUMNS VISUALIZATION ABOVE, ONE CAN NOTICE HOW THE SAME FOOTAgE WAS EDITED REPEATEDLY TO MATCH THE BEAT AND SECTIONS OF THE SONg. THIS VIDEO IS MUCH LONgER THAN THE ORIgINAL FOOTAgE, AND HAS BEEN COMPACTED IN ORDER TO SHOW HOW THE VIDEO WAS SELECTIVELY EDITED.

VISIT HTTP://WWW.YOUTUBE.COM/WATCH?FEATURE=PLAYER_EMBEDDED\&V=BX5-ITIAOPQ. THIS VIDEO WAS UPLOADED TO YOUTUBE 10 JANUARY 2008.

In the Lotus Flower remixes (See image below) we can note that the editing of the videos is quite diverse; the footage is remixed (heavily edited) to match the beat and the overall feel of the selected songs, with the very first videos. 
Two-column visualization of Lotus Flower Remixes

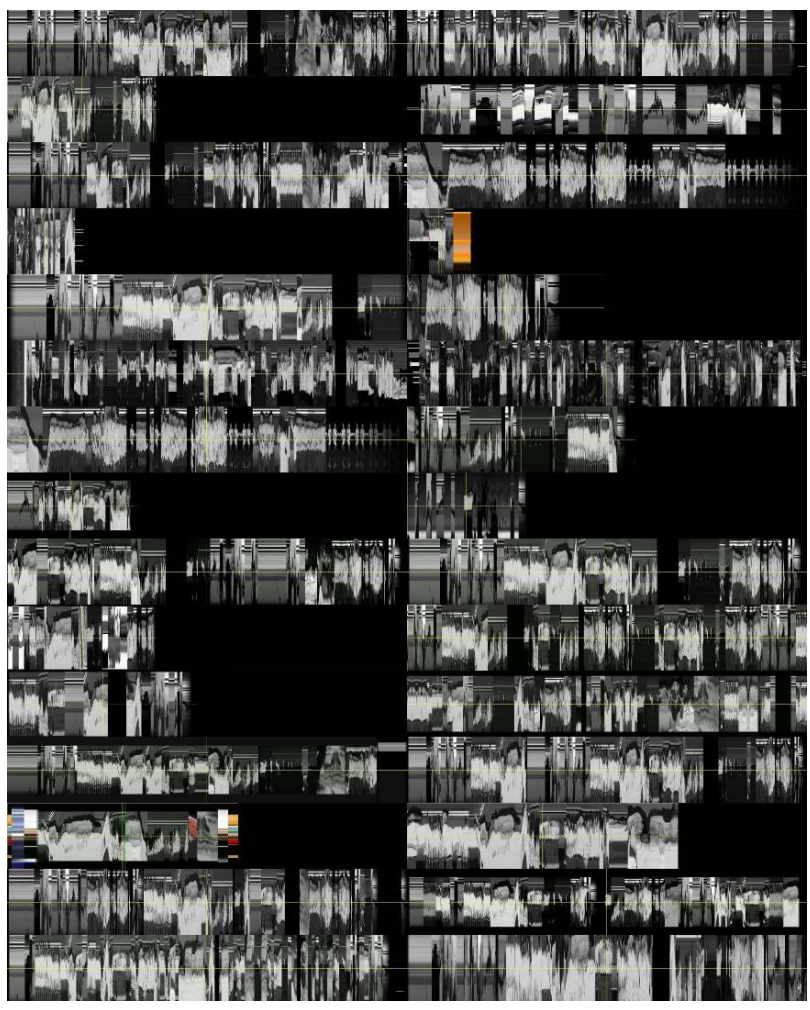

The original video by Radiohead is on the top-left. Most of the videos sliced in this sample were uploaded within the first two weeks after the original video was uploaded by Radiohead 16 February 2011.

For a full list of this visualization visit http://remixtheory.net/remixAnalytics/ and select 'Lotus Flower Video Slices'.

The Downfall remixes (see figure below) consists of video footage that for the most part has been left intact. What is remixed is the fake translation of Hitler's rant. The subtitles for Hitler are sometimes in the middle of the screen, in others at the bottom; sometimes the typeface is small, and at times large. But in the end the video footage is left intact and the translations very much obey the rhythm of the original editing. 


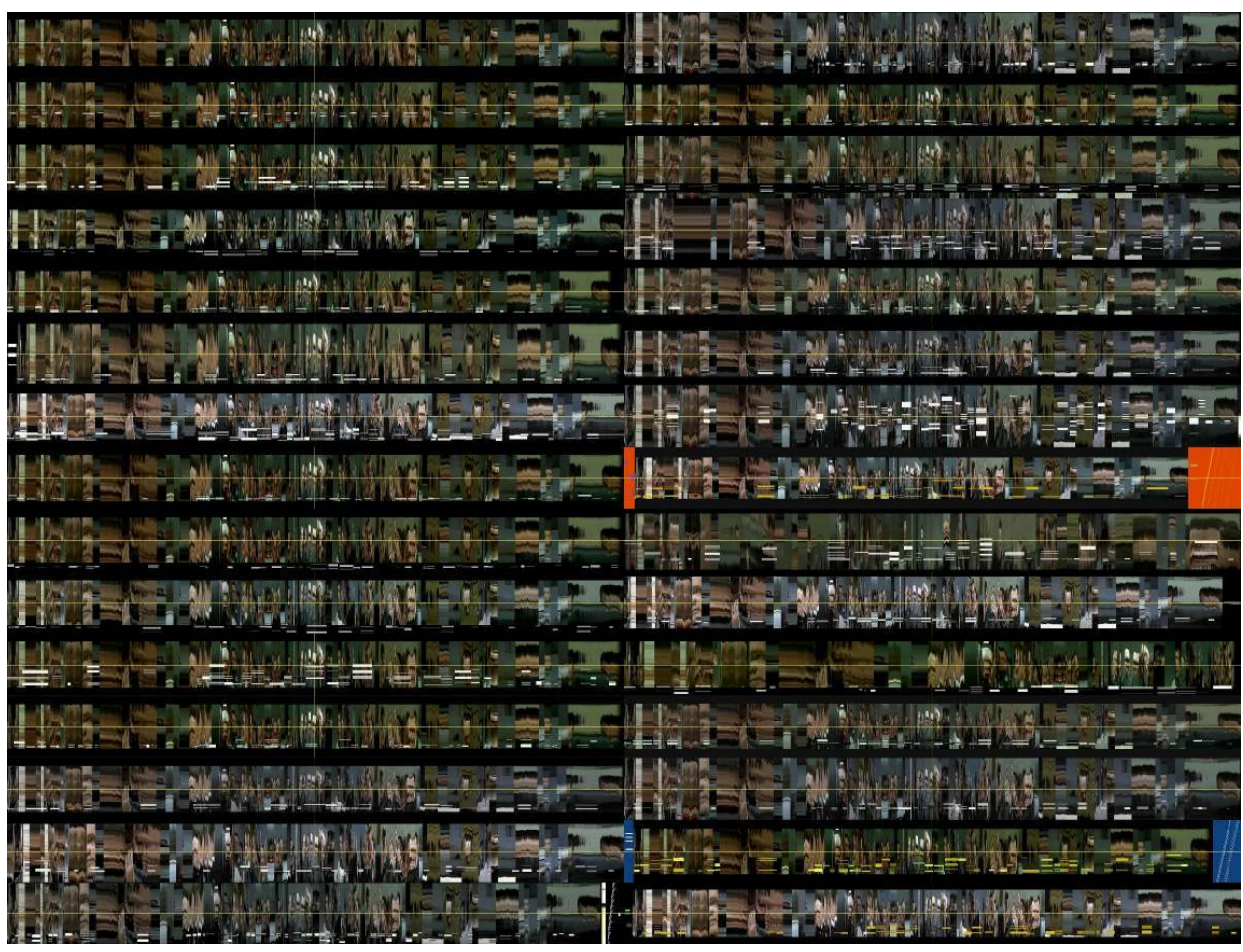

THE ORIgINAL VIDEO WITH NO SUBTITLES IS ON THE TOP-LEFT. VIDEOS SLICED IN THIS SAMPLE WERE UPLOADED BETWEEN 2007 AND 2011. AT THE MOMENT IT IS NOT CERTAIN WHETHER THE 2007 UPLOAD WAS THE fIRST BECAUSE MANY REMIXES HAVE BEEN TAKEN DOWN BY YOUTUBE.

For a full list of this visualization visit: http://remixtheory.net/remixAnalytics/ and select 'Downfall Video Slices'

Visualization of Downfall video, with proper English subtitles

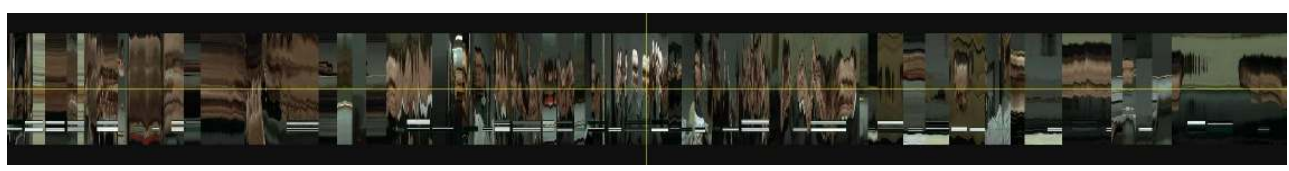

THE THIN HORIZONTAL WHITE BARS NEAR THE BOTTOM OF THE FRAME ARE THE SUBTITLES.

To view this video visit: http://www.youtube.com/watch?v=4bmkUIXp5sk\&feature=related. Some of the remixes present the subtitles in yellow.

Visualization of 'Hitler's Reaction to the new Kiss album', a video remix in which Hitler rants about the album's title 'Sonic Boom'

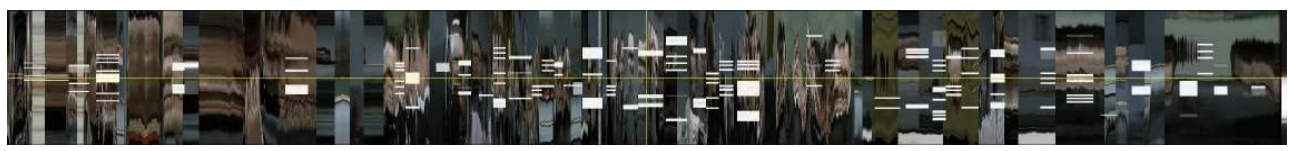

THE SUBTITLES (THE THIN HORIZONTAL WHITE BARS) IN THIS CASE MOVE ALL OVER THE FRAME.

To view this video visit: http://www.youtube.com/watch?v=nwOLfppXhsk\&feature=youtu.be

46 We can note in the three case studies that the approach of remixing is in part defined by the way the original remix or footage was produced. In the Charleston remixes, most contributions leave the video footage intact. No major editing took place until September 2007, that is a year and four months after the first upload. In the Lotus Flower remixes, 
editing of the footage is done from the very beginning, whereas in the Downfall parodies, it does not place at all. Why should this be?

Based on these diagrams and patterns of editing, we can note that the later videos are in fact responses to previous productions. In the Charleston remixes, the video footage is left intact because it is intact in the first remix. With Lotus Flower, the original footage by Radiohead is heavily edited, which gives remixers the license to immediately manipulate the footage in selective fashion - by omitting some parts of the footage while repeating others to match the selected songs. With the Downfall remixes, the result is similar to the Charleston remix: the footage is practically left alone because the meme demands that the basis of the meme be that only the text be remixed; therefore, the only major shift takes place with the placement of translations on the screen: sometimes on the middle, but for the most part at the bottom. The only other shift we can notice with the subtitles is that they may crossover from one shot to the next based on the emphasis of the content that the remixer wants to make. But none of the Charleston and Downfall videos are as heavily edited as the Lotus Flower remixes. It is also worth noting that these are all selective remixes and that they are all dependent on a clear reference to the original source. ${ }^{46}$ If such reference is lost, the remix loses its strength, and becomes either a badly concocted reference, or simply a product on the verge of plagiarism. ${ }^{47}$

One last element to be considered, because it affects the production of the memes, as argued by the study on YouTube funded by Telefonica and the research of Jean Burgess and Joshua Green, ${ }^{48}$ is that due to the viral emphasis on YouTube, online users are most likely to find an already remixed version of a video, and not the original if the remix has enjoyed more views. The exception to this is Lotus Flower, for which YouTube always offers the original video as part of possible selections, on the first page of all results. This is likely because, given Radiohead's popularity, their YouTube channel has a large number of views. For the Charleston, this is not always the case, as the original footage sometimes will not come up with certain video remixes. For the Downfall meme, it is even more difficult to speculate how videos produced before 2007 effect users who currently search for the meme, because they are likely to find videos that are popular, but not necessarily the newest nor the oldest, but rather the most relevant based on the terms used for the search in relation to the number of views.

So, what does all this mean in relation to the production of the remixes? For an average online user who wants to go back to the first source, it is not always possible, if not impossible. It can be done, as I was able to, by doing searches that deliberately consider the time of production; but even when doing this, I was unable to learn which the first Downfall remix was and when it was produced, even when performing a search based on dates. Most importantly, a query by date provides the latest uploads first, which again indicates that YouTube is invested in presenting recent material from its archive. This analysis is a direct example of how time and space have collapsed into search. Ahistoricity is fully at play in modular complexity, and constant updating is the default setting even when chronological requests are made.

\section{Modular Complexity and Remix}

It is now evident that time and space are inherently defined by search, once the informational layer of globalization becomes the new paradigm for private and public interests. This analysis of search on engines, and social spaces such as Flickr and YouTube 
expose the fact that people are informed in fragmentary and essentially modular fashion. This inevitably changes the way individuals acquire knowledge and relate to historical developments. An obvious counter-argument is that people have always searched in fragmentary fashion - no one is able to think in terms of a total body of knowledge. This is true, but the major difference that takes place with modular complexity and search is that people's approach to research, and especially to learn new things on a daily basis is no longer in terms of considering an actual cohesive subject of interest that can then be examined part by part; but rather, from the very beginning, the subject is already seen constructed with various parts or modules. People understand that the subject from its conception is always reconfigurable.

In the realm of entertainment this is best understood when considering the preference to purchase music singles over albums. iTunes gives its members the option to buy singles for just over a dollar. Members can buy the complete album, which is sometimes cheaper than if one were to buy all the songs separately, but the likelihood is that singles will sell the most. Emerging tablet technology, particularly the iPad, is trying to bring back the album concept with special apps to promote the sale of the entire album, and move away from music singles sales, and it remains to see whether this will work. Apple's previous iTunes LP failed. ${ }^{49}$ The current attitude is that a music artist's material is no longer consumed in terms of the sales of a whole (album) but its parts (singles), modules that the music fans can incorporate into a set of personalized compilations (albums) of their own, to be shared with friends, and perhaps even redistribute through p2p networks. ${ }^{50}$ The modular attitude is most importantly affecting the way new generations acquire knowledge, since modularity leads to the concept of multi-tasking. ${ }^{51}$

In the past, I have discussed modular complexity in terms of conflicts being negotiated as separate entities that can co-exist within a space fueled by modular online exchange because each module can be selectively used according to divergent interests:

"[M]odular complexity enables private and public interests to share paradigms of production, and often utilize the same tools to recycle and remix. In brief, the Internet allows cultural exchange with private and public interests to take place with certain autonomy because each activity functions as a module." ${ }^{52}$

The complexity of global information exchange is possible, in other words, because the parts that are exchanged can function autonomously when necessary, and also align themselves with other elements to support a particular project or agenda. Modularity is the foundation of the current flow of information, so it is worthwhile to consider Lev Manovich's definition:

"Media elements, be it images, sounds, shapes, or behaviors, are represented as collections of discrete samples (pixels, polygons, voxels, characters, scripts). These elements are assembled into larger-scale objects but they continue to maintain their separate identity. The objects themselves can be combined into even larger objects -- again, without losing their independence." ${ }^{53}$

Search engines implement modular complexity to filter information according to how algorithms judge a query for little repetition. Modular complexity functions differently when searches are made on Flickr, as we have also seen, given that in the latter, images will not be repeated, but rather a user's profile will become prevalent for many pages at times, based on their overall activity as members of the community. On YouTube, modular complexity informs the way videos become viral. Each video is treated as a separate module that is recalled for several pages, as long as they are relevant to the 
query. The repetition of particular videos at the top of the search, then, affects the type of remix responses YouTube members will produce.

To be fair, it should be noted that users can perform a query with different options. As previously noted, Flickr offers three ways to search their database: relevant, recent, and interesting. These three options, as the words themselves suggest, offer a way to look for material in terms of possible relation to the term submitted in the query, the time material relevant to the term was made, and material that has been tagged, or labeled as interesting according to its flow with Flickr users. YouTube has a similar set of options: Relevance, Upload Date, View Count, and Rating. In YouTube's case, the rating appears to provide a quality element, but in reality, these are based on likes or dislikes of a video, which means that the video's approval or disapproval by the community is linked to the number of views. Google also offers its own set of options, which are available on the left column of the front page, once a search has been performed. Instead, users need to access the advanced search feature, where they can choose: anytime, past 24 hours, past week, past month, past year. In this case, users can select how far they can go on a search, but there is no feature that will present the material strictly chronologically, as the results are still provided according to Google's secret algorithm. Yahoo! offers similar features to Google's as well. Yahoo! users need to select the advanced search option at the top of the main page, from where they can choose: anytime, within the past three months, within the past six months, or within a year. Bing on the other hand does not offer such options, and instead is optimizing a search service that provides query results linked to Facebook's database of friends. ${ }^{54}$

Even when some of the resources offer options to access material chronologically, what is important for this analysis is that this is not the default setting. All resources are by default offering the feature 'relevant' in their own way. And this is understandable, given that people want the correct information swiftly, regardless of when it was produced. But the fact that the pre-existing convention to find relevant information as efficiently as possible was already established in culture before modular search and databases were created, cannot be brought forth to debunk the reality that engines are optimized to offer material of relevance (space) over the history of its production (time). The type of remixes produced will most likely be shallow; meaning, they will likely be direct reactions to the head (top results), as opposed to possibly more relevant and culturally rich productions available in the tail. This could be resolved if it was encouraged for users to do in-depth navigation of the YouTube database. Thus, a paradoxical structure is exposed: a massive amount of information is produced always in reaction to the head of a search. As the Telefonica analysis previously cited demonstrates, the ratio of deep searches is very low. The inevitable result of this query set up is to constantly recycle a comfortable formula that sells well, given that people are likely to see only the most recent material on a search.

\section{Conclusion: Modular Complexity and Ahistoricity}

Previously, in this article, I argued that the archive repositions the relation of historicity to history (the quality of historical authenticity) on an emerging cultural layer, which I refer to as ahistoricity. This shift makes evident that the value of history linked to modular technology is relevant not because of its cultural importance, but because it serves the purpose of translating cultural value to speculative value on to monetary 
value. This is all based on the need to circulate material as much as possible in order to continue support of the global market. The issue at play with such a tendency is that it privileges quantity over quality. When we look at search results on engines, these are optimized to provide users information based on queries. Google appears to be the one closest to a qualitative delivery of information, which is not bound with direct advertisement results. They are clear to separate advertisement from legitimate search results, and the user is able to decide if to click on the ads at the top of the search or on the sidebar. This is not clear, however, with Yahoo!, nor with Bing. But in reality, these online resources are developing software tools that link their services to social media that in one way or another rely on recursion to keep the user's interest.

Modular complexity therefore enables search to be used for divergent interests, as is evident in this analysis. It is the recursive aspect of modular complexity that also encourages the recycling of information because, if there is anything evident about the selective recycling and filtering of search, it is that revenue comes from the recursion of a module. As it is commonly known in economics, for a market to thrive it needs goods to circulate with great efficiency, and this is what is taking place when memes are produced. This is what takes place when a search engine also places a resource at the top of a popular search, even when that link appears only once. The fact that it will be presented consistently on that place each time the same query is made by different people is what enables the recursive element of modular complexity to create the potential growth of markets through pervasive visibility.

Thus the recyling of content is vital to the informational economy. This recyling encourages users to respond, often times, with the very same material reconfigured to express their views or opinions on the subject. This is YouTube's role in terms of recycling. The community functions well because its members feel that they have a voice of expression. Most of the time they will not produce material from scratch but will instead remix something found in the database as a way to make personal statements. This is evident in the rapid response of the video remixes, particularly of Lotus Flower and Downfall. At the same time, remixes may be taken down due to copyright. To this effect, corporations often ask YouTube to take the video remix offline. This is why the average user is unable to access the early remixes of the Downfall meme.

Time collapses into space here and ahistoricity shows that the now rules, when the database is optimized not for historical archiving, at least publicly. It is possible that YouTube keeps copies of all material uploaded, and could allow serious researchers access to their API to perform investigations that may in the end benefit YouTube and the online community as well. But a real possibility for researchers to do in-depth analysis beyond YouTube's viral aspect is limited. Burgess and Green have explained that there is no guarantee that the material in YouTube will be archived long term, or at least properly beyond commercial interests, and that public institutions who may be able to help in organizing and preserving the archive, perhaps outside of YouTube, are unable to because of the complex relationship of YouTube with major corporations and the laws of copyright..$^{55}$ This is the problem with the current state of production of just-in-time delivery of content, which supports research primarily for the pervasive development of platforms that are not designed for technological stability, but rather for the assurance that users will constantly update their hardware and software, thus providing revenue to software companies. Consequently, the informational economy is dependent on a planned obsolescence that pushes the user to constantly update. 
61 From a macro point of view, moving beyond YouTube to global digital production, obsolescence is a major issue for cultural institutions that are invested in archiving material for historical and cultural purposes. For instance, new media artworks are likely to become obsolete in the future once new platforms become irrelevant. Two institutions that are directly effected by this reality are Rhizome and Turbulence. Both online resources are invested in the preservation and proper archival of new media works. But even when there is a deliberate effort to accomplish this, some works of art will not be visible as they were before. A concrete example of this is Not Walls (1996) by Laurel Wilson which uses Apple's Quickdraw, ${ }^{56}$ an online interface that remixes image and text in a 3-D environment. This work is archived on the Turbulence database, but it currently cannot be experienced because current browsers no longer support the apple plug-in. This means that while the archive is preserved it becomes inaccessible unless deliberate effort is made to support older technologies. This, however, is not the interest of the private sector, because they want people to update, and therefore leave behind older technology to keep living on a permanently beta environment. ${ }^{57}$ An example at the most practical and individual level is software such as Microsoft Word, which will not allow a user to open a newer document with an older version of the software. This is done to encourage the user to buy an update of the new software.

In this way the archive in places such as YouTube and Flickr come into conflict with the quality of history, meaning historicity, turning it into ahistoricity, or a lack of concern for actual conservation of material to be accessed byway of new as well as older platforms. This is the layer of ahistoricity that informs search in all the platforms discussed, privileging constant-updating. Those who are invested in knowledge and history as a living discourse must truly consider the stage we are entering with algorithms that privilege the growing economy of the now.

\section{NOTES}

1. This article forms part of my post-doctoral research on Remix and Cultural Analytics in the Department of Information Science and Media Studies at the University of Bergen, in affiliation with The Software Studies Lab at the University of California, San Diego. I want to thank Dag Elgesem and Lev Manovich for their long-term support of my research. For details see http:// remixtheory.net/remixAnalytics

2. I first introduced this concept in 'Remix: The Ethics of Modular Complexity in Sustainability' in CSPA Quarterly, Spring 2010 (http://remixtheory.net/?p=461).

3. Fredric Jameson, Postmodernism: or, the Cultural Logic of Late Capitalism (Durham: Duke University, 1991), 16.

4. Eduardo Navas, 'Regressive and Reflexive Mashups in Sampling Culture'

(http://remixtheory.net/?p=444) and 'Electronic Literature and the Mashup of Analog and Digital Code' (http://remixtheory.net/?page_id=424).

5. Paul Virilio, 'August, 1990: Desert Shield'. Desert Screen (New York: Continuum, 1991), 23.

6. Fredric Jameson, 'Notes on Globalization as a Philosophical Issue'. The Cultures of Globalization

(Eds) Frederic Jameson and Masao Miyoshi (Durham: Duke University Press, 1998), 55. 
7. I also discuss this in 'The Mashup of Analog and Digital Code'.

8. Gina Neff and David Stark, "Permanently Beta," Society Online: The Internet in Context (Eds) Phillip Howard and Steve Jones (New Delhi: Sage, 2004), 173-188.

9. See 'Regressive and Reflexive Mashups'.

10. This word is a combination of local and global. Paul Virilio also uses it in his reflections on the first Gulf War; see Desert Screen, 136-37.

11. John Batelle, 'Google is Born', The Search (Portfolio: New York, 2005), 69-73.

12. This service is called 'Bing and decide with friends' (http://social.discoverbing.com/ \#fbid=KZI-SVfQzYh\&wom=false).

13. Batelle.

14. For engine optimization see the following online pages: Google, 'Webmaster Tool Help', ( http://www.google.com/support/webmasters/bin/answer.py?answer=35291); Yahoo!, 'SEO Basics', (http://styleguide.yahoo.com/resources/optimize-search-engines/seo-basics); Bing, 'Search Engine optimization for Bing' (http://www.bing.com/community/site_blogs/b/ webmaster/archive/2009/09/03/search-engine-optimization-for-bing.aspx).

15. Because Bing provides service to Yahoo! technically it is two search engines that are considered in this analysis., but there are differences in the way material is ranked in Yahoo! and Bing. This is partly to do with the business models in place for the particular corporations.

16. http://en.wikipedia.org/wiki/Remix

17. http://remix.nin.com/

18. http://remix.vg/

19. http://www.remixvintageshoes.com/

20. http://remix.lessig.org/

21. This search was performed on 5 July 2011. The result of the first pages of Bing, Google, and Yahoo! are archived at http://remixtheory.net/remixAnalytics/Search

22. This works best with a specialized term, placed within quotes. In my case, to test my theory, I used "regenerative remix," a term that I developed for my theory of remix. With quotes around the term, Google provided 189 results, which, as I moved through each page was brought down to 65.

23. Bernard J Jansen and Amanda Spink, 'An Analysis of Web Documents Retrieved and Viewed', School of Information Sciences and Technology, The Pennsylvania State University, June 2003, ( http://faculty.ist.psu.edu/jiansen/academic/pubs/pages_viewed.pdf), accessed 10 July 2011.

24. Rob Hof, 'Yahoo! snaps up Flickr', Bloomberg Business Week, 20 March 2005 (http:// www.businessweek.com/the_thread/techbeat/archives/2005/03/yahoo_snaps_up.html), accessed 8 July 2011.

25. This search was performed on 6 July 2011; archived at: http://remixtheory.net/ remixAnalytics/Search.

26. This search was performed on 6 July 2011; archived at: http://remixtheory.net/ remixAnalytics/Search.

27. This search was performed on 6 July 2011; archived at: http://remixtheory.net/ remixAnalytics/Search.

28. Press release, “Google To Acquire YouTube for $\$ 1.65$ Billion in Stock," October 9, 2006, http:// www.google.com/press/pressrel/google_youtube.html, accessed 9 July, 2011.

29. This search was performed on 6 July 6 2011; archived at: http://remixtheory.net/ remixAnalytics/Search.

30. The three studies that I discuss in this section are part of my long-term research, which I am performing for a post-doctoral fellowship at the University of Bergen Norway, in affiliation with the Software Studies Lab at the University of California, San Diego. To learn more about this research, visit http://remixtheory.net/remixAnalytics

31. Ibid. 
32. There are various elements of the videos, particularly the social and political variables, but space does not permit me to explore them in depth here, and I will discuss them in other papers. 33. 'The Charleston Dance Remix', 19 December 2009 (http://knowyourmeme.com/memes/thecharleston-dance-remix) last accessed 10 July 2011.

34. The page was forwarded to me by Jeremy Douglass, a fellow researcher at the Software Studies Lab in San Diego. I found various elements at play in this meme that were also at play in the Charleston meme. See the blog post 'How To Get Down Like Thom Yorke in 10 Easy Steps', 7 March 2011, Death and Taxes (http://www.deathandtaxesmag.com/59030/how-to-get-down-likethom-yorke-in-10-easy-steps/), last accessed 10 July 2011.

35. Studying the "Downfall Parody Remixes" enables me to evaluate two music video memes against a meme that primarily deals with text remixing.

36. For more information, visit the film's official website, http://www.downfallthefilm.com/

37. There are remixes in other languages, but I focused on English parodies because as far as my research demonstrates this is the original language for the meme. Furthermore, dealing with other languages would demand a much longer analysis that would necessitate cultural and linguistic analysis.

38. 'Hitler Learns of Radiohead's Lotus Flower Video Parodies', 19 February 2011. (http:// www.youtube.com/watch?v=Fvo45_kXogs\&feature=player_embedded), accessed 10 July 2011.

39. There are quite a few articles and blogs about the Downfall parodies. The videos that they feature have been taken down. See for example 'Hitler Remixes Are Big - on YouTube', Wired Magazine, 14 May 2008 (http://www.wired.com/underwire/2008/05/adolf-hitler-is/), accessed 20 July 2011.

40. To view the diagram visit http://remixtheory.net/remixAnalytics/Diagrams/ DownfallRemixes.html

41. Jean Burgess \& Joshua Green, YouTube: Online Video and Participatory Culture (Cambridge: Polity, 2010), 76.

42. Ibid, 63.

43. Ibid, $64-68$.

44. Ibid, 70 .

45. Meeyoung Cha, Haewoon Kwak, Pablo Rodriguez, Yong-Yeol Ahn, and Sue Moon, 'I Tube, You Tube, Everybody Tubes: Analyzing the World's Largest User Generated Content Video System' (2007) http://an.kaist.ac.kr/traces/papers/imc131-cha.pdf, 4

46. For the full definition of the selective remix see 'Selective and Reflexive Mashups'.

47. For more on the selective remix, see my text 'Selective and Reflexive Mashups'.

48. For Burgess and Green this is evident based on their assessment of the emphasis of presenting popular videos first, and the fact that YouTube members deliberately find ways to promote their videos to become as popular as possible. Burgess and Green, 74.

49. Ben Sisario, 'Labels and Musicians Enhance Albums for the iPad', New York Times, March 28, $2011 \mathrm{http}: / /$ mediadecoder.blogs.nytimes.com/2011/03/28/labels-and-musicians-enhancealbums-for-the-ipad/, accessed 20 July 2011.

50. Sharing is more difficult to do because of traces placed on $\mathrm{mp} 3$ recordings, but there are still ways around it.

51. David Glenn , 'Divided Attention', The Chronicle of Higher Education, February 28, 2010, http:// chronicle.com/article/Scholars-Turn-Their-Attention/63746/, accessed July 20, 2011

52. Eduardo Navas 'Remix: The Ethics of Modular Complexity in Sustainability', published in the CSPA Quarterly, Spring 2010 (http://remixtheory.net/?p=461).

53. Lev Manovich, The Language of New Media (Cambridge, Massachusetts: 2001), 51.

54. Ibid, footnote 11.

55. Burgess and Green, 89. 
56. Laurel Wilson, Turbulence.org, 1996: http://turbulence.org/walls.htm, accessed 20 July 2011.

57. Neff and Stark.

\section{ABSTRACTS}

If postmodernity consisted of the collapse of time into space, then the time of globalization at the beginning of the twenty-first century consists of the collapse of time and space into search. Culture has entered a stage in which time and space are redefined by modular access to knowledge in unprecedented fashion with the use of search engines. Search redefines the way people come to terms with historical developments that are constantly recycled and remixed with the use of new media technology. A search is usually performed with engines such as Google and Bing; technology that is founded on research that brings together private and public interests

Si la postmodernité a favorisé la dissolution du temps au profit de l'espace, alors le $\mathrm{XXI}^{\mathrm{e}}$ siècle, époque de la globalisation, permet la dissolution du temps et de l'espace dans la fonction «recherche». La culture relève d'une époque où le temps et l'espace sont redéfinis d'une manière totalement innovante par l'accès modulaire au savoir et en prise direct avec les moteurs de recherche. La fonction « recherche " redéfinit la manière dont les gens peuvent s'approprier l'évolution historique constamment recyclée et remixée par la pratique des technologies numériques. Une recherche est généralement entreprise grâce aux moteurs de recherche comme Google ou Bing, qui relèvent de partenariats intégrant sans distinction les sphères privées et publiques

Si la posmodernidad consiste en la disolución del tiempo en el espacio, luego la globalización en el inicio del siglo XXI consiste en la disolución de tiempo y espacio en la función de "búsqueda". La cultura ha entrado en un estadio en el cual, a raíz del uso de motores de búsqueda, el tiempo y el espacio son redefinidos por el acceso modular al conocimiento de una forma inédita. La búsqueda redefine la manera en la que la gente se apropia unos acontecimientos históricos que se encuentran constantemente resignificados y reconstituidos por el uso de las nuevas tecnologías asociadas a los media. La búsqueda se realiza habitualmente a través de dispositivos como Google y Bing, una tecnología fundada en la invetsigación que reúne intereses públicos y privados.

\section{INDEX}

Mots-clés: remix, métadonnées, moteur de recherche, connaissance, technologies des connaissances

Palabras claves: Remix, Meta-Datos, Motor de Búsqueda, Conocimiento, Tecnologías del Conocimiento

Keywords: remix, meta-data, search engine, knowledge, media-technology 


\section{AUTHOR}

\section{EDUARDO NAVAS}

Department of Information Science and Media Studies, University of Bergen, Norway Post-Doctoral Research Scholar

http://www.uib.no/persons/Eduardo.Navas

Software Studies Lab

University of California, San Diego

http://lab.softwarestudies.com/

http://visarts.ucsd.edu/user/view/66 